\title{
Perceptions and attitudes of the nursing staff towards patient
} restraint

\author{
Ziva Roffe*, Marc Gelkopf, Pnina Behrbalk, Yuval Melamed and Avi Bleich
}

Address: Lev-Hasharon Mental Health Center, POB 90000, 42100 Netanya, Israel

* Corresponding author

from WPA Thematic Conference. Coercive Treatment in Psychiatry: A Comprehensive Review

Dresden, Germany. 6-8 June 2007

Published: 19 December 2007

BMC Psychiatry 2007, 7(SuppI I):SI55 doi:10.1 I86/I47I-244X-7-SI-SI55

This abstract is available from: http://www.biomedcentral.com//47I-244X/7/SI/SI55

C) 2007 Roffe et al; licensee BioMed Central Ltd.

\section{Background}

Restraining patients prompts difficult dilemmas and conflicts for the caregivers. With the understanding that the nursing staff plays a significant role in the decision to restrain a patient, we examined the factors and reasons that influence the concept and positions of the nursing staff regarding patient restraint. We examined nurses' attitudes, environmental concerns and emotional response to physical restraint of psychiatric inpatients, using a questionnaire we constructed expressly for this study.

\section{Methods}

$111 / 130(85.4 \%)$ nurses in a psychiatric hospital completed anonymous questionnaires regarding their attitudes towards using physical patient restraints. The findings were analyzed using chi square for dichotomous analysis, t-test, for consecutive analysis and ANOVA and MANCOVA analyses appropriate.

\section{Results}

Nurses reported that the main criteria for restraint were endangerment of the patient's self or surroundings. Bothersome actions and environmental conditions also significantly impacted nurses' decisions to physically restrain patients. Emotional reactions to restraining procedures as experienced by staff and perceived for patients was generally negative. Although the core guideline followed by the nursing staff, being that patient restraint is only appropriate when the patient is a danger to himself or to his surroundings is followed, an important minority of nurses considers restraint as practical means to reduce unruly behavior. The meaning and associations to restraint is influenced by a variety of factors, such as the environmental conditions during or preceding an event, the emotions of the staff, and how the staff perceives the patient's reactions.

\section{Conclusion}

Nurses should be trained to deal with violent patients, establish limits, and recognize the therapeutic aspect of restraints in order to respond assertively. 